\title{
Method to locate the polar cap boundary in the nightside ionosphere and application to a substorm event
}

\author{
A. T. Aikio ${ }^{1}$, T. Pitkänen ${ }^{1}$, A. Kozlovsky ${ }^{1,2}$, and O. Amm ${ }^{3}$ \\ ${ }^{1}$ Department of Physical Sciences, University of Oulu, P.O. Box 3000, FIN-90014, Finland \\ ${ }^{2}$ Sodankylä Geophysical Observatory, Sodankylä, Finland \\ ${ }^{3}$ Finnish Meteorological Institute, Helsinki, Finland
}

Received: 7 December 2005 - Revised: 13 April 2006 - Accepted: 19 May 2006 - Published: 9 August 2006

\begin{abstract}
In this paper we describe a new method to be used for the polar cap boundary (PCB) determination in the nightside ionosphere by using the EISCAT Svalbard radar (ESR) field-aligned measurements by the 42-m antenna and southward directed low-elevation measurements by the ESR $32 \mathrm{~m}$ antenna or northward directed low-elevation measurements by the EISCAT VHF radar at Troms $\varnothing$. The method is based on increased electron temperature $\left(T_{e}\right)$ caused by precipitating particles on closed field lines. Since the Svalbard field-aligned measurement provides the reference polar cap $T_{e}$ height profile, the method can be utilised only when the PCB is located between Svalbard and the mainland. Comparison with the Polar UVI images shows that the radar-based method is generally in agreement with the PAE (poleward auroral emission) boundary from Polar UVI.

The new technique to map the polar cap boundary was applied to a substorm event on 6 November 2002. Simultaneous measurements by the MIRACLE magnetometers enabled us to put the PCB location in the framework of ionospheric electrojets. During the substorm growth phase, the polar cap expands and the region of the westward electrojet shifts gradually more apart from the PCB. The substorm onset takes place deep within the region of closed magnetic field region, separated by about $6-7^{\circ}$ in latitude from the PCB in the ionosphere. We interpret the observations in the framework of the near-Earth neutral line (NENL) model of substorms. After the substorm onset, the reconnection at the NENL reaches within $3 \mathrm{~min}$ the open-closed field line boundary and then the PCB moves poleward together with the poleward boundary of the substorm current wedge. The poleward expansion occurs in the form of individual bursts, which are separated by $2-10 \mathrm{~min}$, indicating that the reconnection in the magnetotail neutral line is impulsive. The poleward expansions of the PCB are followed by latitude dispersed intensifications in
\end{abstract}

Correspondence to: A. T. Aikio

(anita.aikio@oulu.fi) the westward electrojet with high latitudes affected first and lower latitudes later. We suggest that reconnection bursts energize plasma and produce enhanced flows toward the Earth. While drifting earthward, part of the plasma population precipitates to the ionosphere producing latitude-dispersed enhancements in the WEJ.

Keywords. Ionosphere (Polar ionosphere) - Magnetospheric physics (Polar cap phenomena; Storms and substorms)

\section{Introduction}

The polar cap is a region around a geomagnetic pole, which is surrounded by the auroral oval. It is a unique region in the near-Earth space, since the magnetic field lines emanating from the polar cap are open and entry of solar wind plasma to the polar cap ionosphere can take place to form the polar rain precipitation.

The plasma flow within the polar cap ionosphere is typically antisunward with return flows on the dawn and dusk sides, roughly within the auroral oval. It has been shown that this plasma convection pattern can arise from the merging of the southward interplanetary magnetic field (IMF) with the geomagnetic field lines on the dayside magnetopause (Dungey, 1961). During northward IMF, merging may take place poleward of the cusps. Dayside merging creates open field lines, which are carried away with the solar wind. Field lines can be returned in a closed state by nightside reconnection in the distant neutral line (DNL). The balance between the dayside and nightside reconnection rates determines the amount of open flux and is related to the size of the polar cap (Cowley and Lockwood, 1992). Russell (1972) suggested that the two processes may be viewed as two separate timedependent processes. This means that while dayside merging

Published by Copernicus GmbH on behalf of the European Geosciences Union. 
is thought to be controlled by the IMF, magnetotail reconnection may not have a similar strong IMF dependence.

In addition to direct dissipation, the energy tapped from the solar wind is stored as magnetic energy in the geomagnetic tail lobes and can be released during substorms, when a near-Earth neutral line (NENL) may form (McPherron et al., 1973). The factors that control the formation and location of the NENL are still under debate. The reconnection at the NENL starts on closed field lines but may proceed to open field lines, which results in a sudden contraction of the polar cap on the night side.

It has been shown theoretically that the plasma flow through the open-closed boundary in the ionosphere can be utilized to estimate the reconnection electric field in the magnetotail (Vasyliunas, 1984). Crucial for this method is, however, how accurately the open-closed boundary (OCB) can be determined. The ionospheric projection of the OCB is the polar cap boundary (PCB). The most straightforward way to identify the PCB is from satellite particle measurements: by studying the cutoff of polar rain electrons or velocity dispersed ion signatures, type-2 (VDIS-2) (Sotirelis et al., 1999). Polar rain electrons $(<1 \mathrm{keV})$ stem in open field lines from the solar wind, whereas VDIS-2 are assumed to be originated from the reconnection site and subsequently affected by the convection electric field.

In the ionosphere, the poleward boundary of the auroral oval is generally used as a proxy for the PCB. The oval consists of two parts: the discrete oval lies embedded in the diffuse oval, which may extend both poleward and equatorward of the discrete oval (e.g. Kauristie et al., 1999 and references therein). However, one should note that the real PCB may lie at higher latitudes than the poleward boundary of the oval in a situation where no electron precipitation occurs from closed field lines mapping in the vicinity of the distant neutral line, but rather from field lines located earthward of the DNL. Since this issue has remained unsolved, the best what can be done with ionospheric measurements is to use the particle/optical boundary as a proxy for the PCB. Below we will give a short summary of the ionospheric methods used for determining the PCB.

Particle boundaries can be studied by low-altitude polar orbiting satellites (Newell et al., 1996a,b). For automated detection of boundaries by the DMSP satellites, definitions for different boundaries have been constructed. For poleward boundaries, the following definitions are of interest: b3b: the polewardmost electron acceleration event, b5e: the poleward boundary of the auroral oval as determined by an abrupt drop in the electron energy flux, b5i: same for ions and b6: poleward boundary of subvisual drizzle roughly adjacent to the oval. Boundary 5 is identified by a sharp drop in energy fluxes by a factor of at least four. Newell et al. $(1996 a, b)$ note that under active conditions, boundary 5 usually represent the poleward boundary of precipitation. However, often and especially during quiet conditions, a region of low-energy structured ion and electron precipitation at low flux levels exists, which is called subvisual drizzle. When a satellite is moving poleward, the subvisual drizzle terminates either when fluxes drop or when polar rain is encountered.

Global images of the auroral oval can also be used for PCB determination. Baker et al. (2000) compared the poleward auroral emission (PAE) boundary from the Polar Ultraviolet Imager (UVI) with the DMSP poleward auroral oval (b5e) boundary. Detection of the b6 boundary by Polar UVI was not considered realistic. The PAE was determined by using a fixed threshold of auroral brightness as well as a fixed ratio of oval brightness to the maximum value. The optimal values found were 4.3 photons $\mathrm{cm}^{-2} \mathrm{~s}^{-1}$ and 0.3 , respectively. The threshold value was very close to that used by Brittnacher et al. (1999), 4 photons $\mathrm{cm}^{-2} \mathrm{~s}^{-1}$. However, Baker et al. (2000) found a systematic error of $1^{\circ}$ in the PCB by PAE as compared to the particle boundaries. On the other hand, in a case study, Wild et al. (2004) found good correspondence between the PAE by the IMAGE satellite FUV WIC sensor and particle boundaries by FAST and DMSP satellites in the dawn sector. However, the 04-06 MLT sector showed a discrepancy between the WIC (140-180 nm) and SI-13 (130$140 \mathrm{~nm}$ ) sensors: auroral emissions recorded by SI-13 extended to latitudes significantly poleward of the emissions recorded by WIC. So, probably the sensitivity of the sensor plays a role. Global images by the Polar UVI instrument together with low-altitude satellite measurements has been used to monitor the polar cap area by Milan et al. (2003, 2004) and by IMAGE SI12 (proton aurora) instrument by Hubert et al. (2006).

The first attempt to use the incoherent scatter radar (ISR) for PCB detection and reconnection rate estimation in the nightside ionosphere was made by de la Beaujardiere et al. (1991). The PCB was identified as the poleward boundary of the auroral region by following the electron density contour of $3 \cdot 10^{11} \mathrm{~m}^{-3}$ at an altitude of $125 \mathrm{~km}$. For that purpose, the radar was scanning in the meridional plane providing a temporal resolution of 3 to $5 \mathrm{~min}$ and not very wide latitudinal coverage. Utilising a similar ISR experiment, Blanchard et al. $(1995,1996)$ estimated the reconnection rate mapped to the ionosphere, but they used ground-based optical images of the $630.0 \mathrm{~nm}$ emission for PCB determination. Doe et al. (1997) have also used scanning ISR measurements. They calculated the characteristic energy of precipitating electrons from the measured electron densities and compared those with the PCB determined by the all-sky images of the 630.0$\mathrm{nm}$ emission.

Ostgaard et al. (2005) used the EISCAT VHF radar pointing at low elevation angle to a poleward direction together with the IMAGE satellite FUV WIC camera. The method was based on the measurement of the increased electron temperature $T_{e}$ in the nightside F region. Diffuse electron precipitation from the plasma sheet boundary layer or more energetic electron precipitation in the equatorward drifting arcs is expected to increase the electron temperature in the $\mathrm{F}$ region. A median filter was applied to analysed $T_{e}$ data to remove 
unreasonable values and then the boundary was determined for eleven different electron temperatures. The $T_{e}$ value, which correlated best with the FUV images, was selected. In the two events studied, values of $2500 \mathrm{~K}$ and $1800 \mathrm{~K}$ were taken to represent the PCB, respectively.

On the dayside, many IS radar studies have been made in the vicinity of cusp to study pulsed magnetopause reconnection and flux transfer events (e.g. Moen et al., 2004 and references therein).

Coherent HF radars record the boundary between low and high spectral width signals, which can also be used as a proxy for the PC boundary, as demonstrated by Chisham et al. (2004), although this technique is uncertain in the dawn sector. At present, it is unclear precisely what geophysical structure these boundaries represent (Wild et al., 2004).

The typical convection pattern in the ionosphere consists of two cells, as discussed above. On the dusk (dawn) side, the ionospheric flow is eastward (westward) at the high latitudes and westward (eastward) at lower latitudes. The border between these two flow directions is called the convection reversal boundary (CRB). Sometimes the CRB is taken as a proxy for the PCB (e.g. Nishitani et al., 2002). However, it has been shown that in some cases the CRB occurs in the plasma sheet boundary layer (PSBL) and hence on closed field lines (Senior et al., 1994). The CRB is determined by the convection electric field, whereas the magnetic convection reversal boundary (MCRB), recorded by ground magnetometers, is produced by the electrojets. Within the substorm bulge, a westward electrojet is flowing, known as the substorm current wedge (SCW), which corresponds to an eastward plasma flow. Typically, the MCRB is located 0.5$1.5^{\circ}$ of latitude poleward of the CRB in the morning sector (e.g. Amm et al., 2000). In the event discussed by Amm et al. (2003), the PCB measured by Cluster ion instrument was located $3-4^{\circ}$ of latitude poleward of the MCRB in the midnight sector. No systematic study of the relationship between the poleward boundary of the electrojets (MCRB) and the PCB has been conducted to our knowledge.

This paper presents a new method to be used for polar cap boundary estimation based on EISCAT radar measurements of electron temperature changes over a large latitude range in the nightside ionosphere. In the next section, we explain the experimental setup and data analysis and verify the method by the Polar UVI images. Then we apply the method to a substorm event on 6 November 2002 and study especially the relationship between the polar cap boundary and location of the electrojets.

\section{Data analysis}

\subsection{EISCAT measurements}

In all data analysis, we have used the aacgm (altitude adjusted corrected geomagnetic coordinates), for which any

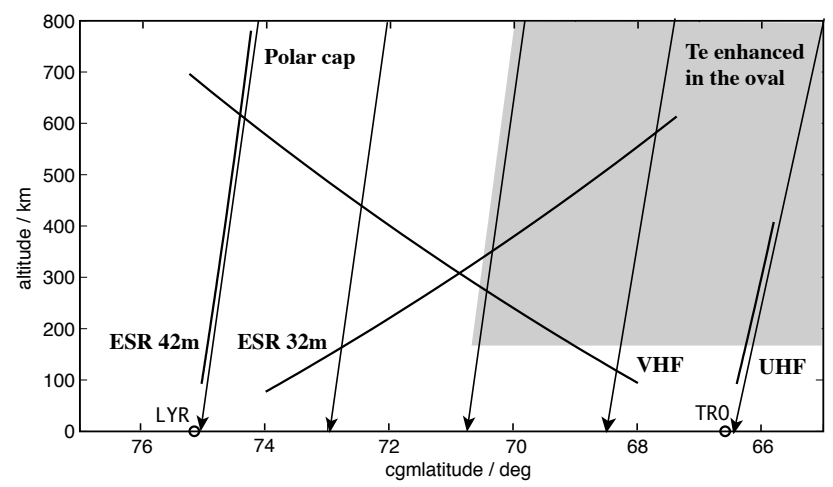

Fig. 1. Schematic figure of the method used in determining the PCB from the EISCAT measurements. Grey-shaded region represents the auroral oval, where $T_{e}$ is enhanced over a wide altitude range.

two points connected by a magnetic field line have the same coordinates (Baker and Wing, 1989), and for brevity, we just denote them as cgm.

The incoherent scatter EISCAT VHF radar, located in Troms $\varnothing$ (geographic: $69.59^{\circ} \mathrm{N}, 19.22^{\circ} \mathrm{E}$, cgm: $66.58^{\circ}$, $102.94^{\circ}$ ), was pointed to $30^{\circ}$ elevation with azimuth of $0.5^{\circ}$ to the west from geographic north. The EISCAT Svalbard Radar (ESR) 32m antenna, located in Longyearbyen (geographic: $78.15^{\circ} \mathrm{N}, 16.03^{\circ} \mathrm{E}$, cgm: $75.22^{\circ}, 111.94^{\circ}$ ), was directed at $30^{\circ}$ elevation to azimuth of $179.5^{\circ}$ to the east from geographic north. So, the radar beams were co-aligned between Troms $\varnothing$ and Longyearbyen with a longitude separation of about $3^{\circ}$. In addition, the ESR $42 \mathrm{~m}$ antenna was measuring field-aligned. The ESR measurement started at 18:00 UT, but the VHF measurement later, at 20:24 UT.

The basic idea of the measurement configuration is shown in Fig. 1. Electron precipitation in the nightside ionosphere increases the electron temperature $T_{e}$ due to the collisional heating of background plasma by the primary and secondary electrons. Since the energy flux of precipitating electrons in the oval is typically higher than that in the polar cap (polar rain precipitation), electron temperature changes can be used to track the polar cap boundary. When a radar is measuring at a low elevation angle, the $T_{e}$ profile along the beam depends both on the horizontal variations in the temperature as well as the height profile of the temperature. Typically, $T_{e}$ increases with altitude. When the PCB is situated between Troms $\emptyset$ and Longyearbyen, the ESR 42m antenna, measuring in the field-aligned direction, can provide the height profile of $T_{e}$ in the polar cap. If now the polar cap $T_{e}$ altitude profile is subtracted from the $T_{e}$ altitude profile along the low elevation antenna beam, a positive value indicates that at the corresponding point $T_{e}$ is enhanced. By searching the polewardmost point where the temperature difference is positive, the PCB can be located.

In practice, the critical factor in such a calculation are the errors of the analysed temperature values. To reduce the 

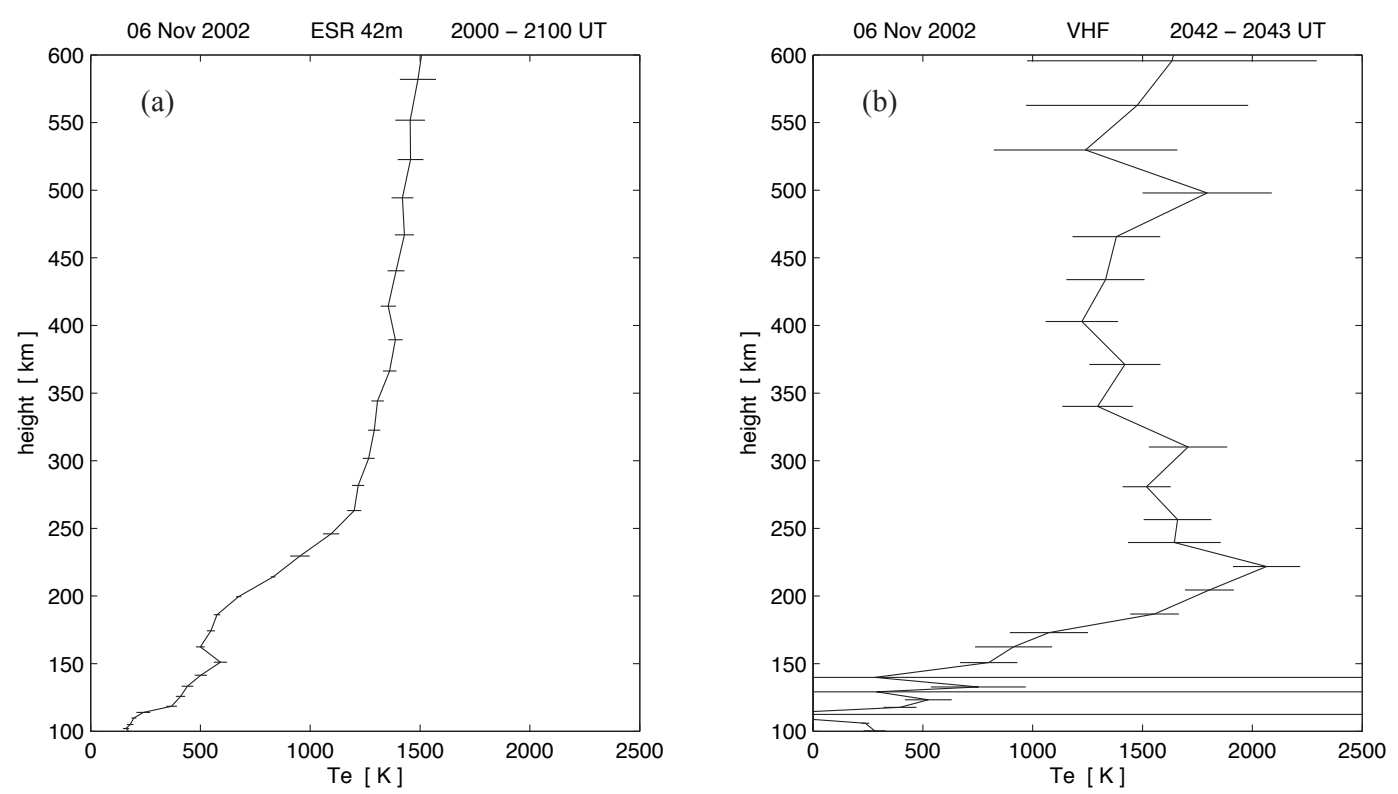

Fig. 2. (a) The polar cap altitude profile of $T_{e}$ by the ESR $42 \mathrm{~m}$ radar and (b) the altitude profile of $T_{e}$ by the low-elevation VHF radar.
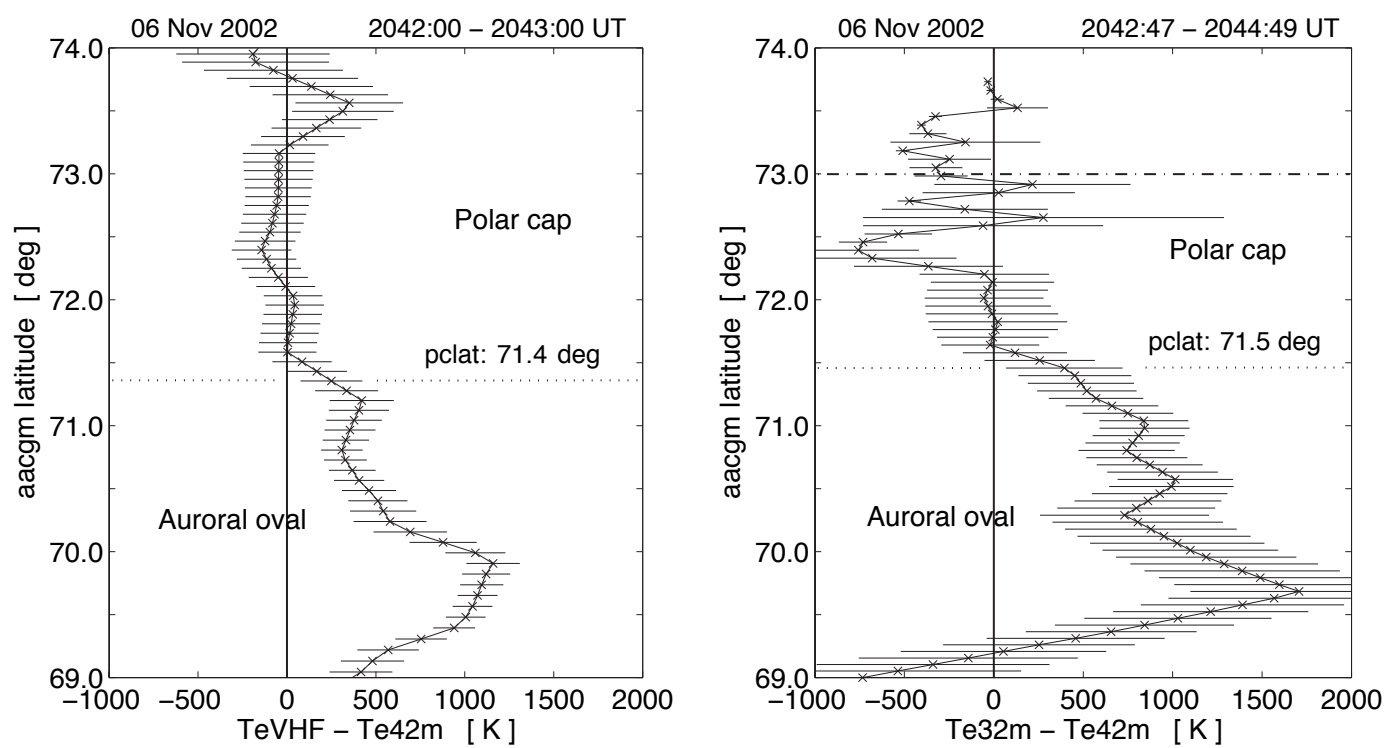

Fig. 3. Left: The polar cap altitude profile of $T_{e}$ by the ESR $42 \mathrm{~m}$ radar (Fig. 2a) subtracted from the altitude profile of $T_{e}$ by the low-elevation northward pointing VHF radar (Fig. 2b) and the result shown as a function of latitude. Right: The polar cap altitude profile of $T_{e}$ by the ESR $42 \mathrm{~m}$ radar (Fig. 2a) subtracted from the altitude profile of $T_{e}$ by the southward pointing low-elevation ESR $32 \mathrm{~m}$ radar as a function of latitude. For the ESR $32 \mathrm{~m}$ data the highest latitude studied is $73^{\circ}$, as shown by the dashed line.

errors in the reference polar cap ESR $42 \mathrm{~m}$ height profile, we analysed the data first with $2 \mathrm{~min}$, then $10 \mathrm{~min}$ and finally $60 \mathrm{~min}$ integration time. During each step, we checked that there were no significant temporal variations in the $T_{e}$ profiles to be integrated together. Actually, F-region electron density showed some variations, which possibly were F-region polar patches, but those did not affect the $\mathrm{F}$ region temperatures. The range resolution used in the analysis phase increases from $3 \mathrm{~km}$ in the lower E region gradually to $30 \mathrm{~km}$ at $600 \mathrm{~km}$. An example of the polar cap $T_{e}$ altitude profile is shown in Fig. 2a.

The ESR $32 \mathrm{~m}$ and VHF data were integrated to $128 \mathrm{~s}$ and $60 \mathrm{~s}$ resolution, respectively. Effectively the 128-s integration time is $64 \mathrm{~s}$, since the two antennas ( $32 \mathrm{~m}$ and $42 \mathrm{~m}$ ) of the ESR radar are swapped at the basic integration time of the measurement $(6.4 \mathrm{~s})$. 


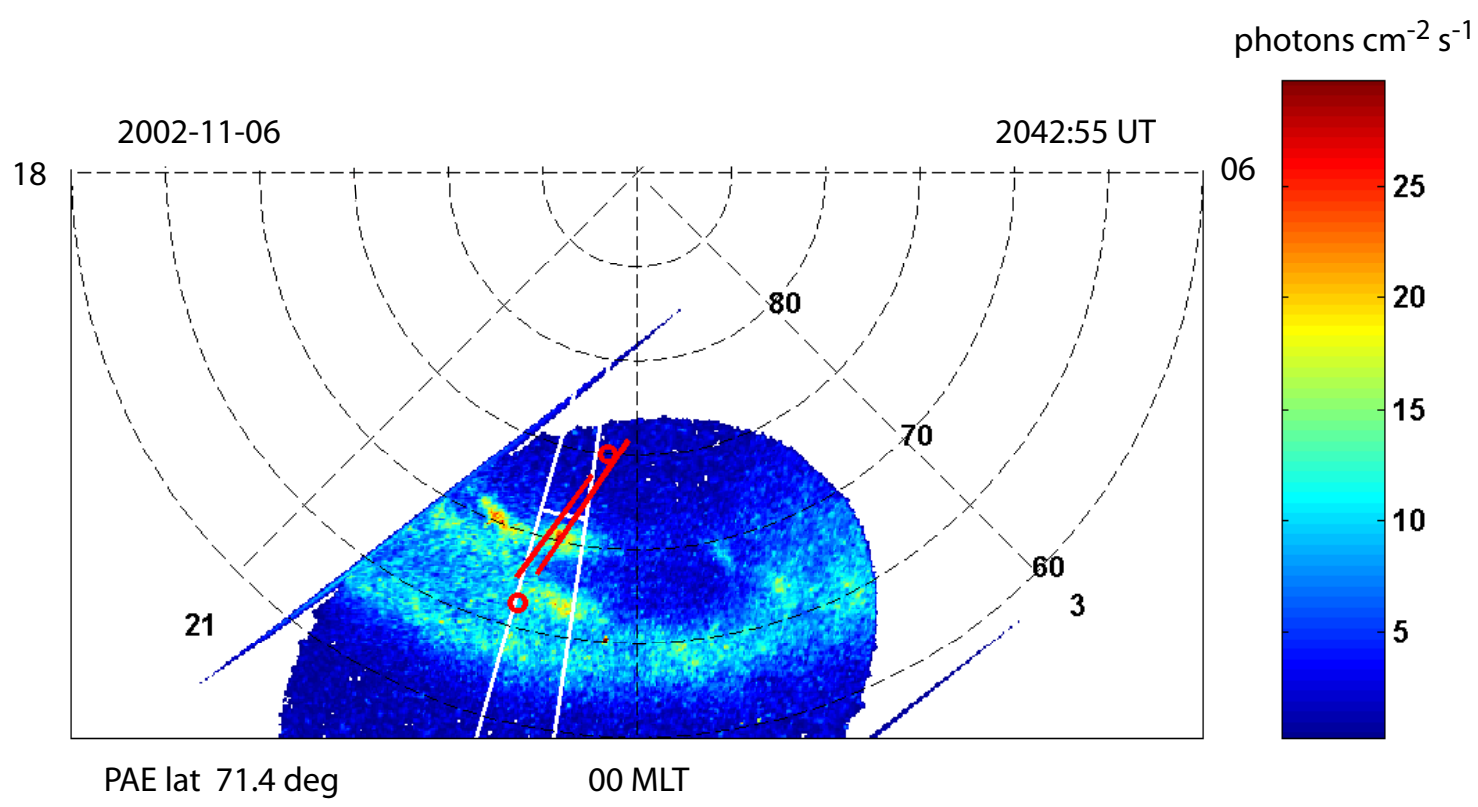

Fig. 4. Polar UVI taken at 20:42:55 UT in geomagnetic coordinates. The MLT zone used in calculating PAE is shown by white lines as well as the calculated PAE. The ESR $32 \mathrm{~m}$ and VHF beam projections are shown in the figure.

The range gates in the analysis were increased as range increased. A typical example of the VHF $T_{e}$ altitude profile is shown in Fig. 2b. In order to be able to subtract from the VHF/ESR $32 \mathrm{~m}$ data the corresponding altitudes of the ESR $42 \mathrm{~m}$ data, all the altitude profiles were interpolated with a height resolution of $5.7 \mathrm{~km}$, which in latitude is about $10 \mathrm{~km}$ for the $30^{\circ}$ elevation angle. However, the real resolution is determined by the range resolution of the original analysed data, which within the studied latitude ranges (see below) provides latitude resolutions from 0.18 to $0.36^{\circ} \mathrm{cgmLat}$ for the VHF radar and from 0.15 to $0.36^{\circ}$ cgmLat for the ESR $32 \mathrm{~m}$ radar.

The lowest altitude, where the method worked, was about $150 \mathrm{~km}$ for the VHF and $200 \mathrm{~km}$ for the ESR $32 \mathrm{~m}$ radar, setting the lowest latitude to about $69^{\circ}$ cgmLat for the VHF and the highest latitude to $73^{\circ}$ for the ESR $32 \mathrm{~m}$ radar. At very long ranges, the signal-to-noise ratio of the data became small, so that effectively the VHF radar could probe the latitude span from $69^{\circ}$ to 73.5 or $74^{\circ}$ and ESR $32 \mathrm{~m}$ from $69^{\circ}$ to 72.5 or $73^{\circ}$ (the searched latitude region was varied a little according to ionospheric conditions affecting the analysed data quality).

The result of subtraction of data in Fig. 2a from that in Fig. $2 b$ is displayed in the left panel of Fig. 3 for latitude range of 69 to $74^{\circ} \mathrm{cgmLat}$. Since the $\Delta T_{e}$ profile often fluctuated around the zero line, we made a routine to look for the highest latitude where $\Delta T_{e}$-error stayed above zero to locate the PCB. In Fig. 3 this latitude is $71.4^{\circ}$ for the VHF radar, while the actual curve crosses the zero line at somewhat higher latitude. Note, that during this time interval, the search was limited below latitudes of $73.5^{\circ}$, so the single data point at an altitude of $500 \mathrm{~km}$ (Fig.2b) was not taken into account.

For comparison, the corresponding temperature difference height profile is shown also for the ESR $32 \mathrm{~m}$ radar in the right panel of Fig. 3. During this time interval, the estimated PCB value of $71.5^{\circ} \mathrm{cgmLat}$ is very close to that by the VHF radar. Fig. 3 also shows, that for the experiments used, the errors were typically larger for the ESR $32 \mathrm{~m}$ data than for the VHF data.

Single points in the altitude profile may have very large errors (especially close to the highest/lowest altitudes searched) and therefore it turned out to be necessary to check manually all the PCB values from the automatic routine and reject false points. Those points were easy to identify from the time series plot, since they were typically sudden jumps to the edges of the searched latitude region.

\subsection{Comparison of Polar UVI and EISCAT polar cap boundaries}

The Polar satellite was imaging the Northern Hemisphere during 18:03-21:01 UT and in this work we use data from the UVI imager with the LBHl (Lyman-Birge-Hopfield spectrum, long wavelengths, $160-180 \mathrm{~nm}$ ) filter (Torr et al., 1995). The auroral luminosity observed with the LBHl filter is directly proportional to the energy flux of the precipitating electrons (Brittnacher et al., 1999). An emission altitude of $120 \mathrm{~km}$ is assumed. The UV Imager provided one frame in about $6 \mathrm{~min}$ with the acquisition time of $37 \mathrm{~s}$. To compare the Polar data with the EISCAT measurements, we selected 


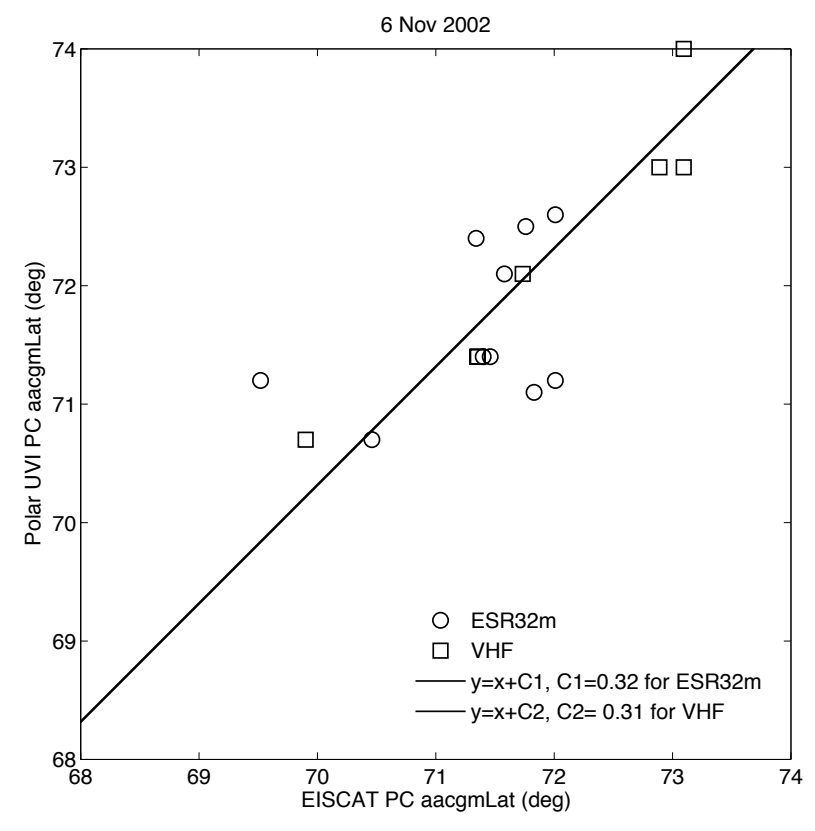

Fig. 5. Comparison of polar cap boundary latitude by Polar UVI and ESR 32m (circles) as well as Polar UVI and VHF (squares). Linear fits to both of the curves are shown, but they overlap. For details, see text.

a sector 0.5 MLT wide containing Troms $\varnothing$ and Longyearbyen and calculated the longitudinal average of the emission intensity with a resolution of $0.5^{\circ}$ in cgm latitude. From these latitudinal intensity profiles, the poleward auroral emission (PAE) latitudes were determined by using the threshold value of 4.3 photons $\mathrm{cm}^{-2} \mathrm{~s}^{-1}$ (Baker et al., 2000; Brittnacher et al., 1999). One such example is shown in Fig. 4 , at 20:42:55 UT when the Polar satellite is already at quite a low latitude. The PAE latitude is marked by a white line in the figure and the locations of the ESR 32m and VHF radar beams are shown by red vectors. In this particular case, the PAE latitude was $71.4^{\circ}$ and the PCB by ESR $32 \mathrm{~m}$ and VHF (see Fig. 3) was $71.4^{\circ}$ and $71.5^{\circ}$, respectively.

In seventeen of the UVI images, PAE boundary values were above $73^{\circ}$ and thus not detectable by the ESR $32 \mathrm{~m}$ radar. The remaining points are compared to the ESR $32 \mathrm{~m}$ PCB and the result is shown in Fig. 5 by circles. Seven common points are found for Polar UVI PAE and the VHF PCB and those are marked by squares in Fig. 5. Ideally, the points would lie in the $y=x$ curve. However, since the PCB values are based on the highest latitude where the curve+error stays above zero, it is presumable that the method gives somewhat lower latitude values than the curve alone would give. Therefore, we made a fit of the form $y=x+c$ to the data sets and as a result, we obtained $\mathrm{c}=0.32^{\circ}$ for the ESR $32 \mathrm{~m}$ data and $\mathrm{c}=0.31^{\circ}$ for the VHF data. So, typically about $0.3^{\circ}$ should be added to the latitude value obtained by the automatic routine.
This comparison shows that the PAE by the Polar UV Imager corresponds quite well to the poleward boundary of the increased $T_{e}$ region in the ionosphere, which we use as a proxy for the polar cap boundary.

Further verification of the method could be obtained by using satellite data, but only one DMSP satellite pass occurred within the area imaged by Polar UVI and measured by EISCAT during the studied time interval. At about 18:41:10 UT the DMSP F15 satellite encountered both the $b 1 e$ "zero-energy" electron boundary and the $b 2 e$ boundary, where the electron average energy stays constant with latitude (start of the main plasma sheet) (Newell et al., 1996a,b). The $b 3 b$ boundary, the polewardmost electron acceleration event, was crossed at 18:43:40 and $b 6$, the poleward boundary of weak precipitation adjacent to the oval, at 18:43:54. Those four boundaries are shown by crosses overlaid on the Polar UVI image taken at 18:40:15 UT in Fig. 6 and an approximate correspondence seems to be visible. However, the PAE boundary, as shown by the white line at an latitude of $74.2^{\circ}$, is located clearly poleward of the $b 6$ boundary at $71.6^{\circ}$. A possible explanation can be found in the time difference: the DMSP satellite passed the poleward boundary of precipitation about $3.5 \mathrm{~min}$ later than the UVI image was taken. The DMSP pass was during a dynamical substorm situation. The ESR 32m data supports the interpretation of the temporal evolution, i.e. during PAE determination at 18:40:15 UT $T_{e}$ was enhanced beyond $73^{\circ}$ (and hence could not be exactly determined), but 18:42:40-18:44:42 UT the PCB had moved to $70.5^{\circ}\left(+0.3^{\circ}\right.$ due to the method $)$, which is very close to the $b 3 b$ value of $70.8^{\circ}$ and not far from the $b 6$ boundary of $71.6^{\circ}$. In addition to the temporal evolution, the UVI image shows an azimuthal gradient in precipitation. The DMSP satellite goes along the evening side boundary of the selected MLT zone, where a double oval-like configuration is seen. This is confirmed by the DMSP particle spectra, which show a gap in precipitation in the middle of the pass (data not shown). So, all in all the poleward edge of energetic precipitation by the DMSP satellite seems to be in agreement with the EISCAT defined PCB boundary and the difference to the PAE boundary can be explained by the temporal change in precipitation.

\section{Substorm event and polar cap boundary}

In this section, we apply the method to locate the PCB to a substorm event on 6 November 2002.

Substorm activity took place in the Scandinavian sector from 18:00 to about 20:30 UT and after that a new substorm growth phase started, close to the local magnetic midnight, which is at about 21:00 UT. We use the magnetic X component of a north-south IMAGE magnetometer chain as input to calculate the equivalent east-west current in the ionosophere using 1-D-upward field continuation method (Vanhamäki et al., 2003). The result from 20:00 to 22:30 UT is shown in 


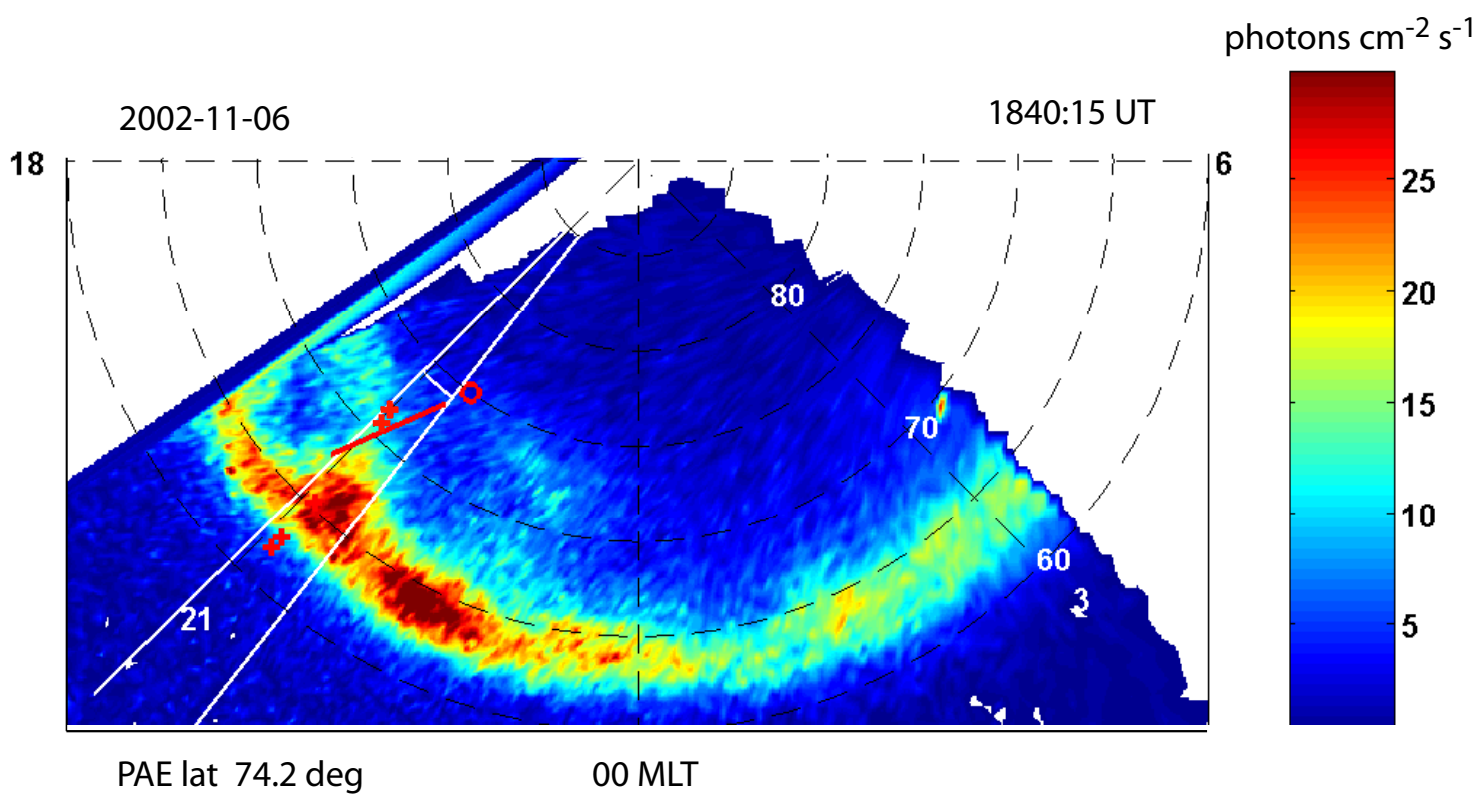

Fig. 6. Polar UVI taken at 18:40:15 UT in geomagnetic coordinates. The MLT zone used in calculating PAE is shown by white lines as well as the calculated PAE. The ESR $32 \mathrm{~m}$ beam projection is shown in the figure. The crosses are the following DMSP boundaries: $b 1 e, b 2 e, b 3 e$ and $b 6$.

6 Nov 2002 lonospheric eq. currents in $\mathrm{mA} / \mathrm{m}$ (>0 eastward)

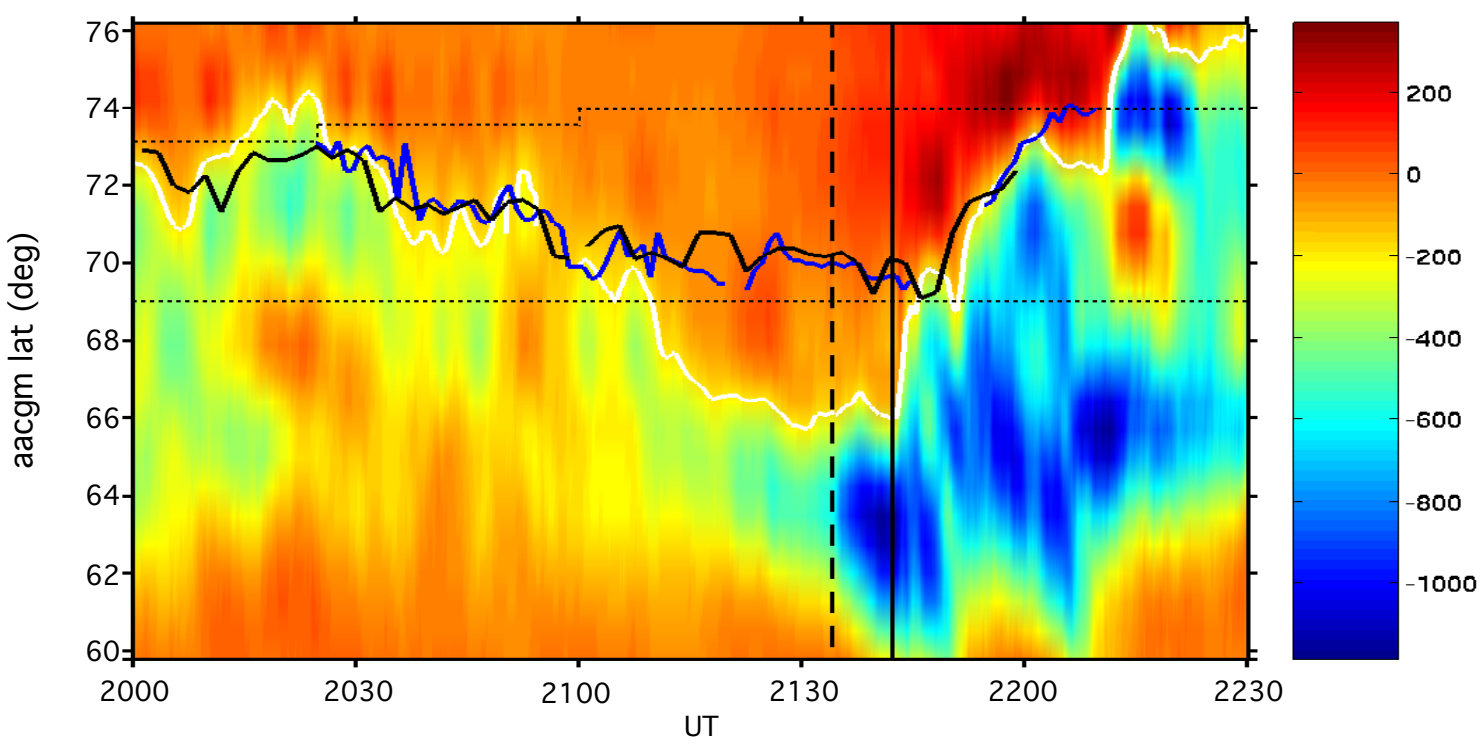

Fig. 7. Equivalent east-west current over a large latitude range as a function of time. The white line indicates the poleward boundary of the WEJ $(-200 \mathrm{~mA} / \mathrm{m})$. The polar cap boundary from ESR 32m (black line) and VHF (blue line) are added. The vertical (solid) dashed line indicates onset of a pseudobreakup at 21:34 UT (substorm onset at 21:42 UT). The horizontal dotted lines indicate the latitude range, where the PCB in this event can be located using the radar data.

Fig. 7. In the calculation, a quiet day is searched to be used in setting the baselines for the stations. To determine the poleward boundary of the westward electrojet (WEJ), we found that the value $-200 \mathrm{~mA} / \mathrm{m}$ is good for this event and this curve is shown as a white line in Fig. 7. Between the most northern mainland station SOR $\left(67.34^{\circ}\right.$ cgmLat $)$ and the Svalbard station HOR $\left(74.13^{\circ} \mathrm{cgmLat}\right)$, there is only one magnetometer station: BJN $\left(71.45^{\circ} \mathrm{cgmLat}\right)$ on Bear Island, so the accuracy within this region of interest is about $1^{\circ}$ of latitude. 
The polar cap boundary from the ESR $32 \mathrm{~m}$ (black line) and the VHF (blue line) radar are also shown in Fig. 7 (with $0.3^{\circ}$ cgmLat added due to the method, see the previous section). In the end of the previous substorm (20:00-20:30 UT), the poleward boundary of the westward electrojet and the PCB coincide within the uncertainty limits. After 20:30 UT, the relatively weak WEJ starts to migrate to lower latitudes. The PCB moves to lower latitudes together with the WEJ until about 21:10 UT, after which a clear separation of the PCB and the WEJ region takes place.

At 21:34 UT a sudden enhancement of the WEJ occurs at very low latitudes, center at about $63^{\circ} \mathrm{cgmLat}$, which is associated with only a small expansion of the WEJ to higher latitudes, from 65 to $66^{\circ} \mathrm{cgmLat}$. The widening to lower latitudes is more pronounced. The minimum of the associated magnetic bay is $-320 \mathrm{nT}$. Because of the lack of a significant $\left(>2^{\circ}\right.$ cgmLat) poleward expansion, we classify this onset preferably as a pseudobreakup (see, e.g. Aikio et al., 1999 and references therein).

At 21:42 UT a rapid poleward expansion of the WEJ takes place, in connection with a sudden brightening of the most equatorward arc in the KEV $\left(66.32^{\circ}\right.$ cgmLat) all-sky camera field-of-view (data not shown). We identify the 21:42 UT onset as substorm onset. The mid-latitude Pi2 (York and Nurmijärvi) show onset at about 21:34 (pseudobreakup onset), with further amplification of pulsations at 21:42 UT (substorm onset).

During the onsets, the PCB was located at 69.5$70^{\circ}$ cgmLat. So, the ionospheric location of the pseudobreakup and substorm onset was situated about $6-7^{\circ}$ cgmLat equatorward of the polar cap boundary. The duration of the pseudobreakup was $8 \mathrm{~min}$.

To study the evolution of the PCB and the WEJ in more detail during substorm expansion, we show Fig. 8. The subsequent poleward expansion after the substorm onset was very rapid, it took only about $3 \mathrm{~min}(11 \mathrm{~min})$ for the poleward boundary of the substorm current wedge to reach to PCB after the substorm (pseudobreakup) onset. The poleward expansion of the SCW is burstlike and even the initial expansion seems to consist of two individual excursions poleward. During the first $30 \mathrm{~min}$ of expansion phase, at least five individual bursts can be distinquished. Each of them starts with a poleward expansion of the SCW poleward boundary and is followed by an increase in the equivalent current density at lower latitudes within the main oval. Intensifications in the current density are latitude dispersed with high latitudes affected first.

We have numbered the bursts in Fig. 8. The identification of individual bursts is not quite unambiquous, but we consider bursts 1, 2, 3, 4 and 5 very clear and suggest that some substructure would exist, e.g. burst 3 would consist of two parts, $3 \mathrm{a}$ and $3 \mathrm{~b}$. Burst 0 is associated with the pseudobreakup. The separation of bursts 1 and 2 is $2 \mathrm{~min}, 2$ and 3 $6 \mathrm{~min}, 3 \mathrm{a}$ and $3 \mathrm{~b} 2 \mathrm{~min}, 3 \mathrm{~b}$ and $47 \mathrm{~min}$ and 4 and $510 \mathrm{~min}$.
Bursts 1 and 2 bring the SCW adjacent to the PCB. Unfortunately, the VHF $T_{e}$ profile contained too many points with large errors during the first $10 \mathrm{~min}$ of substorm onset to be used for the PCB determination. However, the ESR $32 \mathrm{~m}$ data provided the estimate. The small contraction of the SCW poleward boundary after burst 2 is not accompanied by a similar motion in the PCB. Burst 3 brings the SCW again adjacent to the PCB and after that, the SCW and PCB move together until end of burst 4 , after which the poleward boundary of the SCW again separates a little from the PCB. At about 22:10 UT, the PCB is located at a latitude of $74^{\circ} \mathrm{cgmLat}$, which is the highest latitude, which can be observed with the radar method in this case (marked with the horizontal dotted line). Burst 5 occurs at about 22:10 UT and this burst brings the poleward boundary of the SCW (and obviously also the PCB, though it can't be traced anymore) to the latitude of Longyearbyen $\left(75.5^{\circ} \mathrm{cgmLat}\right)$, so that precipitation fills also the field-aligned ESR $42 \mathrm{~m}$ antenna beam (data not shown). After burst 5, the westward electrojet is divided into two parts: one flowing in the main oval and the other at high latitudes. Between these regions, no significant electrojet flows, so probably a double oval configuration is formed (Elphinstone et al., 1995).

In the EISCAT time-height/latitude colour surface profiles of different parameters, some equatorward or poleward moving structures could be identified. We traced some of the most pronounced structures and could identify an equatorward moving auroral structure emanating from the PCB at about 22:10 UT, which is added to Fig. 8. The auroral structure was first seen by the ESR radar as an enhancement of electron density (dark green curve), then at higher altitudes and longer ranges, as an enhancement in the electron temperature (red curve). Then the VHF radar caught it: at longer ranges and higher altitudes as an enhancement of $T_{e}$ (magenta curve), and finally when the structure approached Troms $\varnothing$ and came to lower altitudes within the beam, as an enhancement of $N_{e}$ (outside the plotted time span). So, even though we don't have optical data, we are confident that we observe an auroral structure. Since we have no optical data available, the shape of the structure is not known. The longitudinal width of the structure in this case is at least $3^{\circ}$, which is the separation of the two EISCAT beams. The auroral structure had an equatorward velocity component of about $400 \mathrm{~m} / \mathrm{s}$. We will discuss these observations in more detail in the next section.

\section{Discussion}

We will first summarise the new method we have used for the PCB determination. Diffuse electron precipitation from the plasma sheet boundary layer or discrete electron precipitation associated with drifting auroral arcs is expected to increase the electron temperature in the $\mathrm{F}$ region. For field-aligned currents to heat the electron gas, very small 
6 Nov 2002 lonospheric eq. currents in mA/m (>0 eastward)

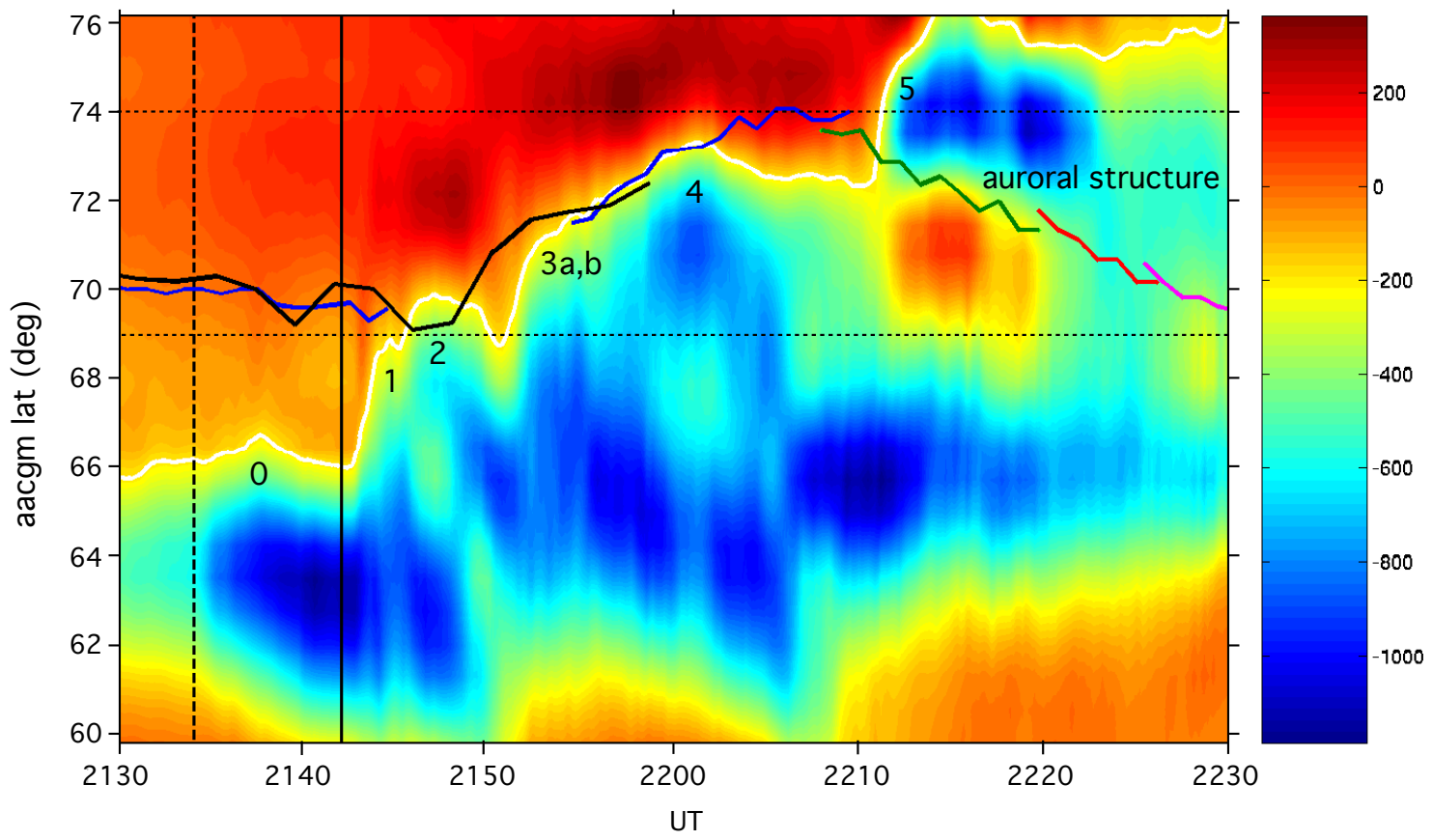

Fig. 8. Equivalent east-west current and the PCB during substorm in the same format as Fig. 7. Substorm intensifications are numbered and the location of the auroral structure is shown. For details, see text.

horizontal scales and very large currents are needed; those are expected at the edges of discrete arcs (Zhu et al., 2001).

Increased electron temperature in the nightside ionosphere for the polar cap boundary determination has been utilised also by Ostgaard et al. (2005). By using simultaneous optical measurements with the IMAGE FUV WIC camera, they searched a fixed value for the increased $T_{e}$ to be used as a proxy for the PCB. A fixed value may be problematic, since for low elevation radar measurements, different latitudes correspond to different altitudes and, in general, $T_{e}$ depends on altitude. In this work, we compare the low elevation temperature profile to the temperature altitude profile in the polar cap. For the method to work, Longyearbyen (the site of ESR measurements) must be in the polar cap. In addition, no cross-polar arcs may be in the field-of-view of the ESR $42 \mathrm{~m}$ antenna. Polar cap patches didn't seem to affect the temperature profiles.

Comparison with the Polar UVI LBHl band showed that the method is viable at least in some conditions. The measurements in this study are made in the nightside winter ionosphere, during substorm growth and expansion.

The advantages of the method are the high temporal and spatial resolution. The resolutions to be achieved depend on the radar codes used (their efficiency) and finally on the resolutions used in the data analysis, which rely on ionospheric conditions. The primary factor is electron density: for large densities high temporal and spatial resolutions can be used whereas for low-density ionosphere the resolutions must be reduced. In this study, we utilised 1 and 2 min temporal resolutions and spatial resolutions which in latitude ranged from about $0.2^{\circ}$ to $0.4^{\circ}$. This method can also provide a continuous determination of the PCB for several hours, unlike lowaltitude satellite measurements. The disadvantage is that the PCB can be located only at one point and no azimuthal information is gained with a fixed beam position. If two radars are available, as in this study (VHF and the ESR 32m antenna), the PCB can be located at two points. However, since during the experiments the longitudinal separation of antenna beams was only $3^{\circ}$, the differences were small. In the future, one could plan experiments, where the low-elevation antenna(s) would move and provide a limited azimuthal view.

The new technique to map the polar cap boundary was applied to a substorm event. Simultaneous measurements by the MIRACLE magnetometers enabled us to put the PCB location in the framework of ionospheric electrojets. In the following, we will discuss the observations in the light of the current understanding of substorm dynamics.

During a substorm growth phase, the magnetic flux in the tail lobes increases, cross-tail current intensifies and the polar cap expands, moving the auroral oval equatorward. In the studied event, this occurs 20:20-21:34 UT. An interesting feature is that while the PCB and the westward electrojet first move together equatorward, during the last $15 \mathrm{~min}$ of the growth phase the WEJ shifts gradually to lower latitudes and separates more and more from the PCB. 
It is generally accepted that close to a substorm onset, both the formation of the near-Earth neutral line (NENL) and the tail current disruption (CD) take place. The main dispute is the order of events. In the NENL model, the substorm starts with a formation of a neutral line in the mid-tail $\left(20-30 R_{E}\right)$, which produces earthward-directed high speed flows transporting flux, mass and energy into the near-Earth region. As a consequence, the near-Earth cross tail current disrupts. In the CD model the primary cause for substorm onset are plasma instabilities developing in the near-Earth region at downtail distances of $6-10 \mathrm{R}_{e}$, which lead to the current disruption and the substorm current wedge formation. A rarefaction wave propagates tailwards and launches reconnection in the midtail (Lui, 1996; Shiokawa et al., 1998).

In the ionosphere, the SCW can easily be located by magnetometers. However, there is no generally accepted signature for the NENL in the ionosphere. At the moment reconnection at the NENL in the mid-tail reaches open field lines, a plasmoid is formed and reconnection starts to destroy open flux, which can be visible as the poleward expansion of the oval (contraction of the polar cap) in the nightside ionosphere.

Pseudobreakups are often observed prior to substorm onsets. Pseudobreakups are characterized as localized, relatively weak and short-lived events. However, the most obvious criterion to separate pseudobreakup from substorm onset is the lack of significant poleward expansion (Ohtani et al., 1993; Aikio et al., 1999). Several studies have shown that pseudobreakups don't differ from substorms in magnetospheric signatures: they are associated with dipolarizations (Ohtani et al., 1993; Koskinen et al., 1993) and even reconnection at the NENL (Aikio et al., 1999).

The data available in this event supports the well known fact that substorms start usually well inside the closed field line region. We are not able to tell which process happens first in the magnetotail: NENL formation or disruption of the cross-tail current. We see the intensification of the WEJ at pseudobreakup onset, which we interpret as a partial disruption of the tail current and the initial build-up of the substorm current wedge. In several studies, it has been shown that reconnection at the NENL starts within a few minutes of pseudobreakup or substorm onset. However, Baker et al. (2002) studied an event where reconnection in the mid-tail preceeded the ground onset even by $7 \mathrm{~min}$. One possibility is that during a pseudobreakup, reconnection occurs at low rate. The rapid poleward expansion at substorm onset is probably related to the increase in the reconnection rate at the NENL. In this study, it took $3 \mathrm{~min}$ (11 min) from the substorm (pseudobreakup) onset for the SCW to expand to the polar cap boundary, which may be interpreted as the time for enhanced reconnection at the NENL to reach open lobe field lines. After that, the PCB (open-closed boundary) contracted poleward together with the expanding substorm current wedge.
The poleward expansions of the SCW and the PCB occurred burstlike and at least five individual bursts separated by $2-10$ min were observed during the first half an hour. The actual duration of the rapid poleward expansion in the events was typically a few minutes. The observation of burstlike development of substorm expansion is not new. E.g. Nakamura et al. (1994) noted that expansion phase consits typically of a number of injections and expansions, each with timescales of 2-8 min. Aikio et al. (1999) found that pseudobreakups and substorm intensifications were separated by about 5 to $15 \mathrm{~min}$. Sergeev et al. (2000) suggests that the characteristic time scale of the bursts, visible in many ionospheric and magnetospheric parameters, is typically $2-3 \mathrm{~min}$.

Figure 8 shows that in events $1-4$, the sudden poleward expansion is followed by an intensification of the westward electrojet at lower latitudes, within the main oval. The intensification of the electrojet is associated with enhanced precipitation, as evidenced by the field-aligned UHF radar at Tromsø (data not shown). The WEJ intensifications show a clear latitude dispersion with high latitudes affected first. We suggest that the burstlike poleward expansions of the PCB are associated with burstlike enhancements in the reconnection rate at the near-Earth neutral line. Reconnection burst energizes plasma and produces enhanced flow toward the Earth. While drifting earthward, part of the plasma population may precipitate to the ionosphere to produce the observed latitude-dispersed intensifications in the WEJ.

Our results are in agreement with the study by Sergeev et al. (2005), who used a radial configuration of several satellites in the tail. They observed that at the main onset, the activity propagated from a midtail reconnection region $\left(\mathrm{XGSM}<-16 \mathrm{R}_{e}\right)$ earthwards and thus was favorable to the NENL scenario.

Sergeev et al. (2000) suggest a model where each reconnection pulse generates localized reconnected flux tubes, which contain fast flowing heated plasma. Braking of the fast flow at the boundary of closed flux tubes can result in further plasma heating and injection and an inward propagating fast wave. Also, the reconnection pulse itself can generate electromagnetic wave pulses, which travel to the inner magnetosphere and accelerate plasma.

In our event, the most intense part of the SCW is all the time several degrees equatorward of the PCB. Only during the latter part of the expansion phase (bursts 4 and 5), significant westward currents flow close to the polar cap boundary. After burst 5, the current structure resembles the double oval configuration.

In the study by Ostgaard et al. (2005) the PCB was found to fluctuate at ULF frequencies (10-15 min periods) in the evening sector during substorm expansion phase. The observations occurred obviously after the initial poleward expansion. It is plausible that the initial rapid burstlike expansions occur within a limited MLT sector with a timescale of 2-10 min, as shown in this study and those cited above. Later, different dynamic behaviour of the PCB motions may 
take place, depending on the magnetospheric and solar wind drivers.

In the plasma sheet, reconnection bursts are believed to be associated with observed transient, localized fast flows of plasma, called also bursty bulk flows (BBFs) or flow bursts, which transport magnetic flux to inner magnetosphere (Angelopoulos et al., 1994). The auroral signatures of fast flows may vary, but the so called auroral streamer is identified as one possible manifestation of the fast flow. Auroral streamers are finger-like, mainly north-south aligned auroral forms (though they may sometimes be very much tilted to the eastwest direction) that develop at the poleward boundary of the auroral oval from where they intrude equatorward with velocities of 1-5 km/s (Sergeev et al., 1999; Amm and Kauristie, 2002). Substorm streamers appear typically about $10 \mathrm{~min}$ after the substorm onset and they develop inside the substorm bulge.

In this study, an auroral structure was observed to emanate from the double oval. However, the measured equatorward velocity component $(400 \mathrm{~m} / \mathrm{s})$ of the auroral structure is clearly lower than the typical velocity of streamer intrusion; the duration of the structure (about $25 \mathrm{~min}$ ) is also rather long. In the absence of optical observations of this structure, we suggest that the auroral form is a discrete auroral arc, drifting equatorward with plasma convection. Formation of a discrete arc close to the PCB simultaneously with a reconnection burst at the NENL, is an interesting observation and not reported before to our knowledge.

\section{Conclusions}

We have presented a new method to be used for polar cap boundary determination in the nightside ionosphere by using the ESR field-aligned radar measurements on Svalbard by the $42 \mathrm{~m}$ antenna and north-south directed low-elevation radar measurements from Svalbard (ESR 32m antenna) and/or mainland Troms $\varnothing$ (VHF radar). The method is based on increased electron temperature caused by precipitating particles on closed field lines. Since the Svalbard field-aligned measurement provides the reference polar cap $T_{e}$ height profile, the method can be utilised only when the PCB is located between Svalbard and the mainland. Comparison with the Polar UVI images on 6 November 2002, showed that the radar-based method is generally in agreement with the PAE (poleward auroral emission) boundary from Polar UVI.

The new method to locate the PCB was applied to a substorm event on 6 November 2002, together with the 1-D upward continuation method of magnetic data from the MIRACLE network to estimate the location and intensity of the electrojet currents. The main results were as follows.

- In the beginning of substorm expansion, the poleward boundary of the WEJ and the PCB are separated by about $4^{\circ}$ cgmLat and substorm onset occurs well inside the closed field line region.
- If reconnection at the NENL starts during the pseudobreakup, it occurs at low rate for the first $8 \mathrm{~min}$. Substorm onset is associated with a rapid poleward expansion of the substorm current wedge, which in 3 min reaches the PCB, after which the PCB and SCW expand together poleward. We interpret that it takes 3 min for the reconnection at the NENL to reach open field lines.

- Substorm development is burstlike with individual bursts separated by $2-10 \mathrm{~min}$. We suggest that the bursts are produced by the impulsive reconnection at the NENL.

- Intensification of the westward electrojet in the main oval shows latitude dispersion with high latitudes affected first after each reconnection burst. We suggest that they occur as a result of reconnection bursts, which energize plasma and produce enhanced flow toward the Earth. While drifting earthward, part of the plasma population precipitates to the ionosphere.

- The burst of poleward expansion that produces the double oval configuration, is associated with a formation of a discrete auroral structure, probably an auroral arc, close to the PCB. The arc drifts equatorward and reaches finally the main oval.

Acknowledgements. We thank G. Parks for the Polar UVI data. The EISCAT scientific association is supported by Suomen Akatemia (Finland), Centre Nationale de la Recherche Scientifique (France), Max-Planck-Gesellschaft (Germany), Norges A1menvitenskapelige Forskningsård (Norway), Naturvetenskapliga Forskningsrådet (Sweden), and Particle Physics and Astronomy Research Council (UK). We are grateful to R. Kuula from the University of Oulu for help in the EISCAT data analysis. The MIRACLE network is operated as an international collaboration under the leadership of the Finnish Meteorological Institute. The IMAGE magnetometer data are collected as a Finnish-German-NorwegianPolish-Russian-Swedish project. The DMSP particle detectors were designed by D. Hardy of AFRL, and data obtained from JHU/APL. We thank D. Hardy, F. Rich, and P. Newell for its use. The authors thank the SAMNET team for magnetometer data. SAMNET is a PPARC National Facility operated by Lancaster University. The work by A. Kozlovsky has been supported by the Academy of Finland.

Topical Editor I. A. Daglis thanks J. Wild and another referee for their help in evaluating this paper.

\section{References}

Aikio, A. T., Sergeev, V. A., Shukhtina, M. A., Vagina, L. I., Angelopoulos, V., and Reeves, G. D.: Characteristics of pseudobreakups and substorms observed in the ionosphere, at the geosynchronous orbit and in the mid-tail, J. Geophys. Res., 104, 12 263-12 287, 1999.

Amm, O. and Kauristie, K.: Ionospheric signatures of bursty bulk flows, Surveys in Geophys., 23, 1-32, 2002. 
Amm, O., Janhunen, P., Opgenoorth, H. J., Pulkkinen, T. I., and Viljanen, A.: Ionospheric shear flow situations observed by the MIRACLE network, and the concept of Harang Discontinuity, AGU monograph on magnetospheric current systems, Geophysical Monograph 118, 227-236, 2000.

Amm, O., Aikio, A., Bosqued, J.-M., Dunlop, M., et al.: Mesoscale structure of a morning sector ionospheric shear flow region determined by conjugate Cluster II and MIRACLE ground-based observations, Ann. Geophys., 21, 1737-1751, 2003.

Angelopoulos, V., Kennel, C. F., Coroniti, F. V., Pellat, R., Kivelson, M. G., Walker, R. J., Russell, C. T., Baumjohann, W., Feldman, W. C., and Gosling, J. T.: Statistical characteristics of bursty bulk flow events, J. Geophys. Res., 99, 21 257-21 280, 1994.

Baker, K. and Wing, S.: A new magnetic coordinate system for conjugate studies at high latitudes, J. Geophys. Res., 94 , 91399143, 1989.

Baker, J. B., Clauer, C. R., Ridley, A. J., Papitashvili, V. O., Brittnacher, M. J., and Newell, P. T.: The nightside poleward boundary of the auroral oval as seen by DMSP and the ultraviolet imager, J. Geophys. Res., 105, 21 267-21 280, 2000.

Baker, D. N., Peterson, W. K., Eriksson, S., Li, X., Blake, J. B., Burch, J. L., Daly, P. W., Dunlop, M. W., Korth, A., Donovan, E., Friedel, R., Fritz, T. A., Frey, H. U., Mende, S. B., Roeder, J., and Singer, H. J.: Timing of magnetic reconnection initiation during a globalmagnetospheric substorm, Geophys. Res. Lett., 29(24), 2190, doi:10.1029/2002GL015539, 2002.

de la Beaujardiere, O., Lyons, L. R., and Friis-Christensen, E.: Sondrestrom radar measurements of the reconnection electric field, J. Geophys. Res., 96, 13 907-13 912, 1991.

Blanchard, G. T., Lyons, L. R., Samson, J. C., and Rich, F. J.: Locating the polar cap boundary from observations of $6300 \AA$ auroral emission, J. Geophys. Res., 100, 7855-7862, 1995.

Blanchard, G. T., Lyons, L. R., de la Beaujardiere, O., Doe, R. A., and Mendillo, M.: Measurement of the magnetotail reconnection rate, J. Geophys. Res., 101, 15 265-15 276, 1996.

Brittnacher, M., Fillingim, M., Parks, G., Germany, G., and Spann, J.: Polar cap area and boundary motion during substorms, J. Geophys. Res., 104, 12 251-12 262, 1999.

Chisham, G., Freeman, M. P., and Sotirelis, T.: A statistical comparison of SuperDARN spectral width boundaries and DMSP particle precipitation boundaries in the nightside ionosphere, Geophys. Res. Lett., 31(2), L02804, doi:10.1029/2003GL019074, 2004.

Cowley, S. W. H. and Lockwood, M.: Excitation and decay of solar wind-driven flows in the magnetosphere-ionosphere system, Ann. Geophys., 10, 103-115, 1992.

Dungey, J. W.: Interplanetary field and the auroral zones, Phys. Res. Lett., 6, 47-48, 1961.

Doe, R. A., Vickrey, J. F., Weber, E. J., Gallagher, H. A., and Mende, S. B.: Ground-based signatures for the nightside polar cap boundary, J. Geophys. Res., 102, 19989-20 005, 1997.

Elphinstone, R. D., Hearn, D. J., Cogger, L. L., et al.: The double oval auroral distribution, 2., The most poleward arc system and the dynamics of the magnetotail, J. Geophys. Res., 100, $12093-$ $12102,1995$.

Hubert, B., Milan, S. E., Grocott, A., Blockx, C., Cowley, S. W. H., and Gérard, J.-C.: Dayside and nightside reconnection rates inferred from IMAGE FUV and Super Dual
Auroral Radar Network, J. Geophys. Res., 111, A03217, doi:10.1029/2005JA011140, 2006.

Kauristie, K., Weygand, J., Pulkkinen, T. I., Murphree, J. S., and Newell, P. T.: Size of the auroral oval: UV ovals and precipitation boundaries compared, J. Geophys. Res., 104, 2321-2331, 1999.

Koskinen, H. E. J., Lopez, R. E., Pellinen, R. J., Pulkkinen, T. I., Baker, D. N., and Bösinger, T.: Pseudobreakup and substorm growth phase in the ionosphere and magnetosphere, J. Geophys. Res., 98, 5801-5813, 1993.

Lui, A. T. Y.: Current disruption in the Earths magnetosphere: Observations and models, J. Geophys. Res., 101, 1996, 13 06$13088,1996$.

McPherron, R. L., Russel, C. T., and Aubry, M.: Satellite studies of magnetospheric substorms on August 15, 1978, 9. Phenomenological model for substorms, J. Geophys. Res., 78, 3131-3149, 1973.

Milan, S. E., Lester, M., Cowley, S. W. H., Oksavik, K., Brittnacher, M., Greenwald, R. A., Sofko, G., and Villain, J.-P.: Variations in the polar cap area during two substorm cycles, Ann. Geophys., 21, 1121-1140, 2003.

Milan, S. E., Cowley, S. W. H., Lester, M., Wright, D. M., Slavin, J. A., Fillingim, M., Carlson, C. W., and Singer, H. J.: Response of the magnetotail to changes in the open flux content of the magnetosphere, J. Geophys. Res., 109, A04220, doi:10.1029/2003JA010350, 2004.

Moen, J., Lockwood, M., Oksavik, K., Carlson, H. C., Denig, W. F., van Eyken, A. P., and McCrea, I. W.: The dynamics and relationships of precipitation, temperature and convection boundaries in the dayside auroral ionosphere, Ann. Geophys., 22, 1973-1987, 2004.

Nakamura, R., Baker, D. N., Yamamoto, T., Belian, R. D., Bering III, E. A., Benbrook, J. R., and Theall, J. R.: Particle and field signatures during pseudobreakup and major expansion onset, J. Geophys. Res., 99, 207-221, 1994.

Newell, P. T., Feldstein, Y. I., Galperin, Y. I., and Meng, C.-I.: Morphology of nightside precipitation, J. Geophys. Res., 101, 10737-10 748, 1996a.

Newell, P. T., Feldstein, Y. I., Galperin, Y. I., and Meng, C.-I.: Correction to "Morphology of nightside precipitation" by Newell, P. T., Feldstein, Y. I., Galperin, Y. I., and Meng, C.-I., J. Geophys. Res., 101, 174்19-17421, 1996 b.

Nishitani, N., Ogawa,T., Sato, N., Yamagishi, H., Pinnock, M., Villain, J.-P., Sofko, G., and Troshichev, O.: A study of the dusk convection cells response to an IMF southward turning, J. Geophys. Res., 107, 1036, 10.1029/2001JA900095, 2002.

Ohtani, S., Anderson, B. J., Sibeck, D. G., et al.: A multisatellite study of a pseudo-substorm onset in the near-Earth magnetotail, J. Geophys. Res., 98, 19355-19367, 1993.

Ostgaard, N., Moen, J., Mende, S. B., Frey, H. U., Immel, T. J., Gallop, P., Oksavik, K., and Fujimoto, M.: Estimates of magnetotail reconnection rate based on IMAGE FUV and EISCAT measurements, Ann. Geophys., 23, 123-134, 2005.

Russell, C. T.: The configuration of the magnetosphere, in Critical Problems of Magnetospheric Physics, edited by: Dyer, E. R., National Academy of Sciences, Washington D.C., 1-16, 1972.

Senior, C., Delcourt, D., Cerisier, J.-C., Hanuise, C., Villain, J.P., Greenwald, R. G., Newell, P. T., and Rich, F. J.: Correlated observations of the boundary between polar cap and nightside auroral zone by HF radars and the DMSP satellite, Geophys. Res. 
Lett., 21, 221-224, 1994.

Sergeev, V. A., Sauvaud, J.-A., Popescu, D., Kovrazhkin, A., Lutsenko, V. N., Zelenyi, L. M., Syrjäsuo, M., Viljanen, A., Pulkkinen, T., Kudela, K., Kokubun, S., and Mukai, T.: Plasma sheet ion injections into the auroral bulge: correlative study of spacecraft and ground observations, J. Geophys. Res., 105, $18465-$ $18482,2000$.

Sergeev, V. A., Liou, K.,Meng, C.-I., Newell, P. T., Brittnacher, M., Parks, G., and Reeves, G. D.: Development of auroral streamers in association with localized impulsive injections to the inner magnetotail, Geophys. Res. Lett., 26, 417-420, 1999.

Sergeev, V. A., Kubyshkina, M. V., Baumjohann, W., Nakamura, R., Amm, O., Pulkkinen, T., Angelopoulos, V., Mende, S. B., Klecker, B., Nagai, T., Sauvaud, J.-A., Slavin, J. A., and Thomsen, M. F.: Transition from substorm growth to substorm expansion phase as observed with a radial configuration of ISTP and Cluster spacecraft, Ann. Geophys., 23, 2183-2198, 2005.

Shiokawa, K., Baumjohann, W., Haerendel, G., Paschmann, G., Fennel, J. F., Friis-Christensen, E., Lühr, H., Reeves, G. D., Russel, C. T., Sutcliffe, P. R., and Takahashi, K.: High-speed ion flow, substorm current wedge, and multiple $\mathrm{Pi} 2$ pulsations, J. Geophys. Res., 103, 4491-4507, 1998.
Sotirelis, T., Newell, P., Meng, C.-I.: Low Altitude Signatures of Magnetotail Reconnection, J. Geophs. Res., 104, 17311-17321, 1999.

Torr, M., Torr, D. G., Zukic, M., Johnson, R. B., Ajello, J., Banks, P., Clark, K., Cole, K., Keffer, C., Parks, G., Tsurutani, B., and Spann, J.: A far ultraviolet imager for the International SolarTerrestrial Physics Mission, Space Sci. Rev., 71, 329-383, 1995.

Vanhamäki, H., Amm, O., and Viljanen, A.: 1-dimensional upward continuation of the ground magnetic field disturbance using spherical elementary current systems, Earth Planets Space, 55, 613-625, 2003.

Vasyliunas, V. M.: Steady state aspects of magnetic field line merging, Magnetic Reconnection in Space and Laboratory Plasmas, edited by: Hones Jr., E. W., AGU, Washington, D.C., Geophys. Monogr. Ser., 30, 25-31, 1984.

Wild, J. A., Milan, S. E., Owen, C. J., Bosqued, J. M., Lester, M., Wright, D. M., Frey, H., Carlson, C. W., Fazakerley, A. N., and Réme, H.: The location of the open-closed magnetic field line boundary in the dawn sector auroral ionosphere, Ann. Geophys., 22, 3625-3639, 2004.

Zhu, H., Otto, A., Lummerzheim, D., Rees, M. H., and Lanchester, B. S.: Ionosphere-magnetosphere simulation of smallscale structure and dynamics, J. Geophys. Res., 106, 1795-1806, 2001. 